Letter to Editor

\section{Hot cholecystectomy}

\author{
Esam Aboutaleb* \\ Ealing Hospital, Uxbridge Road, UB1 3HW, London, UK
}

Acute cholecystitis is a common general surgery disease which may require hospital admission. Delayed or early cholecystectomy is the definitive treatment. Availability of theatre slots may postpone cholecystectomy for weeks. I am writing this letter to explain the importance of early cholecystectomy programme and the necessity of support such programme by hospital managers. I will rationalize the concept of such program and its clinical and economic benefits.

There are many strong evidences that early laparoscopic cholecystectomy (ELC) is a better option than delayed laparoscopic cholecystectomy (DLC) for management of acute cholecystitis. For example, a meta-analysis study showed ELC as safe and effective as DLC and it is associated with lower hospital costs, fewer work delay lost and greater patient satisfaction [1]. Furthermore, US Medicare database that include 29818 elderly patients with acute cholecystitis found a higher risk for mortality over the following two years in patients who were discharged without surgery compared with patients who underwent cholecystectomy in the initial hospitalization [2].

The risk of hospital re-admission after first attack of acute cholecystitis has been studied in a population -based analysis of the clinical course of 10304 patients with acute cholecystitis who discharged without cholecystectomy. Such analysis showed that the probability of a gall stone related A\&E visit or admission within 6 weeks, 12 weeks and 1 year was 14\%, 19\% and 29\% respectively [3]. This will increase the gall stone disease burden and decrease patients' satisfaction.

Per NICE guidelines we should offer ELC (to be carried out within 1 week of diagnosis) to patients with acute cholecystitis. Patients who had pancreatitis secondary to gallbladder stones should have laparoscopic cholecystectomy in the index admission [4]. NICE full health economy report showed that ELC burden is 2728.27 in compare to 3686.21 for DLC [5]. Furthermore, 2018/2019 NHS tariff for emergency

\author{
More Information \\ *Address for Correspondence: Esam Aboutaleb, \\ Ealing Hospital, Uxbridge Road, UB1 3HW, \\ London, UK, Email: e.aboutaleb@nhs.net; \\ esammma@hotmail.com \\ Submitted: 08 November 2019 \\ Approved: 19 November 2019 \\ Published: 20 November 2019 \\ How to cite this article: Aboutaleb E. Hot \\ cholecystectomy. Arch Surg Clin Res. 2019; 3: \\ 077-077. \\ DOI: dx.doi.org/10.29328/journal.ascr. 1001040 \\ Copyright: (C) 2019 Aboutaleb E. This is an open \\ access article distributed under the Creative \\ Commons Attribution License, which permits \\ unrestricted use, distribution, and reproduction \\ in any medium, provided the original work is \\ properly cited.
}

D) Check for updates

laparoscopic cholecystectomy is between 6885 to 3872 pounds, while it is 3731 to 2080 pounds only for an elective case.

To sum up, ELC is as safe as DLC with potential lower mortality risk in elderly patients. In addition to eliminate the risk of re-admission after first attack of cholecystitis and decrease health care burden of gall bladder stones disease.

\section{References}

1. Wu Xd, Tian X, Liu MM, Zhao S, Zhao S. Meta-analysis comparing early versus delayed laparoscopic cholecystectomy for acute cholecystitis. Br J Surg. 2015; 102: 1302-1313.

PubMed: https://www.ncbi.nlm.nih.gov/pubmed/26265548

2. Riall TS, Zhang D, Townsend CM Jr, Kuo YF, Goodwin JS. Failure to perform cholecystectomy for acute cholecystitis in elderly patients is associated with increased morbidity, mortality, and cost. J Am Coll Surg. 2010; 210: 668-677.

PubMed: https://www.ncbi.nlm.nih.gov/pubmed/20421027

3. De Mestral C, Rotstein OD, Laupacis A, Hoch JS, Zagorski B, et al. A population-based analysis of the clinical course of 10,304 patients with acute cholecystitis, discharged without cholecystectomy. J Trauma Acute Care Surg. 2013; 74: 26-30.

PubMed: https://www.ncbi.nlm.nih.gov/pubmed/23271073

4. NICE clinical guidelines. Gallstones disease: diagnosis and management. 2014.

5. National Institute for Health and Care Excellence (UK). Gallstone Disease: Diagnosis and Management of Cholelithiasis, Cholecystitis and Choledocholithiasis. NICE Clinical Guidelines, No. 188. Internal Clinical Guidelines Team (UK). 2014.

PubMed: https://www.ncbi.nlm.nih.gov/pubmed/25473723 